\title{
Renalase a Potential Marker of Ischemia Reperfusion Injury Post Living Donor Liver Transplantation
}

\author{
AHMED M. ABDUL GHANI, M.Sc.*; AHMED YAMANY, M.D.*; SAMAH ABD EL-HAMID, M.D.**; \\ MOSTAFA A. EL-SHAZLY, M.D.*** and MOHAMED S. MOGAWER, M.D.* \\ The Departments of Internal Medicine*, Clinical \& Chemical Pathology** and General Surgery \& Liver Transplantation***, \\ Faculty of Medicine, Cairo University
}

\begin{abstract}
Background: Ischemia refers to diminished blood supply, causing a lack of oxygen and when blood supply is reestablished this is reperfusion. The Ischemia-Reperfusion $(\mathrm{I} / \mathrm{R})$ process is a common event after living donor liver transplantation, trauma, and hemorrhagic shock. Renalase, a ubiquitous flavoprotein, is highly expressed in kidney, liver, heart, skeletal muscles and adipose tissues. Renalase has been verified that it is the only enzyme involved in the catecholamine metabolism that can be secreted into the blood cycle hitherto.

Considering renalase close relationship with oxidative stress, renalase is thought to play a role, or at least responsive, in the process of hepatic ischemia reperfusion injury.

Aim of Study: To demonstrate whether serum Renalase can be used as a potential biomarkers of hepatic ischemia reperfusion injury following living donor liver transplantation especially when combined with the standard LFT panel.

Patients and Methods: The present study was conducted on 50 patients with End Stage Liver Disease (ESLD) undergoing Living Donor Liver Transplantation (LDLT). Patients were evaluated pre-operatively laboratory by using the ChildPugh score and Model for End-Stage Liver Disease (MELD) Score and radiological by abdominal Doppler ultrasonography. Intra-operative evaluation of patients included: Operative details including ischemia time, intraoperative bleeding and amount of blood transfused. Post-operative workup included daily examinations as regards vital signs, drains and fluid balance. Daily measurement of CBC, LFT and KFT was done for seven days.
\end{abstract}

Results: By comparing different laboratory data day seven to laboratory data on day one post-living donor liver transplantation, there was a statistically significant decline regarding AST, ALT, INR reflecting graft function, our study demonstrated no statistically significant correlation between serum Renalase levels and operative ischemia time predisposing to ischemia reperfusion injury.

Conclusion: Clinical treatment decisions based on the serial detection of renalase activities in the blood did not help

Correspondence to: Dr. Ahmed M. Abdul Ghani, The Department of Internal Medicine, Faculty of Medicine, Cairo University in early detection and possible prevention of hepatic ischemia reperfusion injury post-living donor liver transplantation to improve the clinical outcomes of liver transplantation.

Key Words: Hepatic ischemia reperfusion injury - Renalase - Liver transplantation.

\section{Introduction}

ALTHOUGH major advances have been achieved in liver transplantation procedures and the efficient use of immunosuppression, hepatic ischemia reperfusion injury continues to adversely affect hepatic allograft function and survival. Ischemia refers to diminished blood supply, causing a lack of oxygen; when blood supply is re-established after ischemia this is reperfusion. The Ischemia-Reperfusion $(\mathrm{I} / \mathrm{R})$ process occurs in about $10 \%$ of early graft failure [1]. During the hypoxic and reperfusion phases of IRI hepatocellular death may occur, hepatic IRI can be divided into 2 phases, initial phase is characterized by activation of Kupffer Cells (KCs), which release proinflammatory cytokines and Reactive Oxygen Species (ROS) [2]. Hepatocyte damage later on occurs after expression of chemokines and adhesion molecules causing recruitment of inflammatory cells. during this process hepatocytes undergo apoptosis [3]

Renalase, a ubiquitous flavoprotein, which is highly expressed in kidney, liver, heart, skeletal muscles and adipose tissues, the human renalase gene is located on chromosome 10 at q23.33, effectively degrade catecholamines. Human renalase mRNA include 4 variants, renalase type 1 is well conserved, with signal peptide at the Nterminal, a FAD-binding site and amine oxidase domain, it has $13.2 \%$ amino acid identity of Monoamine Oxidase A (MAO-A), however it's different from MAO-A when regarding catecholamine's breakdown [4] 
Renalase has been verified that it is the only enzyme involved in the catecholamine metabolism that can be secreted into the blood cycle hitherto (5)

Previous studies indicated that renalase is multifunctional and closely related to oxidative stress conditions such as stroke, heart and liver transplantation, or acute kidney injury. Considering its tight relationship with oxidative stress, renalase is thought to play a role, or at least responsive, in the process of hepatic ischemia reperfusion injury เซ.

\section{Patients and Methods}

50 patients from El-Manial Specialized Hospital, Cairo University were enrolled in this study with End Stage Liver Disease (ESLD) listed for Living Donor Liver Transplantation (LDLT). Patients were recruited in the period from March 2014 to July 2017. Their ages ranges from 20-64 years with a mean value of $49.28 \pm 9.28$. They were $36(72 \%)$ males and $14(28 \%)$ females.

\section{Inclusion criteria:}

1- Adult (more than 18 years old) patients undergoing liver transplantation.

2- Both genders were included.

3- Patients agreed to participate in the study.

\section{Exclusion criteria:}

1- Sepsis.

2- Evidence of AKI before surgery: Abrupt (within 48 hours) absolute increase in the serum creatinine concentration of $\geq 0.3 \mathrm{mg} / \mathrm{dL}$ from baseline, or increase in the serum creatinine concentration of $\geq 1.5$ times baseline, which is known or presumed to have occurred within the prior seven days or oliguria of less than $0.5 \mathrm{~mL} / \mathrm{kg}$ per hour for more than six hours.

3- Prior kidney transplantation.

4- Patients on potentially nephrotoxic drugs.

5- Chronic kidney disease patients; preoperative serum creatinine level greater than $4.0 \mathrm{mg} / \mathrm{dL}$, or end-stage renal disease (estimated glomerular filtration rate e-GFR $<60 \mathrm{~mL} / \mathrm{min}$ ).

\section{Methods:}

Pre-operatively patients were subjected to through history and physical examination, including age, gender, comorbid diseases (diabetes, hypertension, and dyslipidemia) and concomitant medications (Renin-Angiotensin-Aldosterone System
(RAAS) blockers and diuretics). Before surgery patients were evaluated by using the Child-Pugh score and Model for End-Stage Liver Disease (MELD) Score, Complete Blood Picture (CBC), Liver Function Tests (LFT), prothrombin concentration, Kidney Function Tests (KFT), electrolytes and radiological by abdominal Doppler ultrasonography. Intra-operative evaluation of patients included: Operative details as ischemia time, anhepatic phase duration (the anhepatic phase was defined as the time from the physical removal of the cirrhotic liver from the recipient to recirculation of the graft), intraoperative bleeding. Post-operative workup included daily examinations as regards vital signs, drains and fluid balance, daily measurement of CBC, LFT and KFT was done for seven days. Calcineurin Inhibitor (CNI) levels were checked regularly. Doppler ultrasound was done to assess graft homogeneity, biliary complications, portal trunk and hepatic vessels. Specific laboratory investigations including immunoassay of serum Renalase six hours, one week after transplantation.

\section{Renalase principle of the assay:}

The microtiter plate provided in this kit has been pre-coated with an antibody specific to or serum Renalase. Standards or samples were added to the appropriate microtiter plate wells with a biotin-conjugated polyclonal antibody preparation specific for serum Renalase. Avidin conjugated to Horseradish Peroxidase (HRP) was added to each microplate well and incubated. Then a substrate solution was added to each well. Only those wells that contain, biotin-conjugated antibody and enzyme-conjugated Avidin will exhibit a change in color. The enzyme-substrate reaction was terminated by the addition of a sulphuric acid solution and the color change was measured spectrophotometrically at a wavelength of $450 \mathrm{~nm} \pm 2 \mathrm{~nm}$. The concentration of the markers in the samples was then determined by comparing the O.D. of the samples to the standard curve.

\section{Detection range:}

Serum renalase its level ranges from 0.78 to $50 \mathrm{ng} / \mathrm{mL}$. The standard curve concentrations used for the ELISA's assay were ranged from zero to $50 \mathrm{ng} / \mathrm{ml}$.

\section{Calculation of results:}

The mean absorbance was calculated for each set of duplicate standards, controls and samples, and the average zero standard optical density was subtracted. The standard curve was plotted using Sigma plot software, with standard concentration on the $\mathrm{x}$-axis and absorbance on the $\mathrm{y}$-axis. The 
best-fit straight line was drawn through the standard points.

\section{Statistical methods:}

Data were coded and entered using the statistical package SPSS Version 16. Data was summarized using mean, standard deviation for the quantitative variable. Comparisons between data was done using analysis of variance (ANOVA) with multiple comparisons post hoc test in quantitative variables. $p$-values less than 0.05 were considered as statistically significant. Correlations between measured parameters and laboratory data were done using spearman correlation coefficient.

\section{Declaration of ethics:}

This study was approved by the review board of Kasr Al-Aini Hospital. Oral and written informed consent was obtained from all patients according to Helsinki guidelines of research ethics.

\section{Results}

This prospective study was conducted on 50 patients had undergone living-donor liver transplantation. Their ages range from 20-64 years with a mean value of $49.28 \pm 9.28$. They were $36(72 \%)$ males and $14(28 \%)$ females.

On comparing different laboratory data at day seven post liver transplant to laboratory data on day 1 there was a significant difference of most laboratory data with improvement AST, ALT and INR and hemoglobin at day seven post transplantation than at day 1 (Table 1).

On comparing renalase mean level at day one and day seven there was a highly significant decline of its level at day 7 compared to day one ( $p 0.004)$ (Table 2).

In our study, serum renalase at day one did not show any correlation with graft ischemia time (anhepatic phase) with correlation coefficient: 0.12 and $p$-value 0.4 shown in Fig. (1).

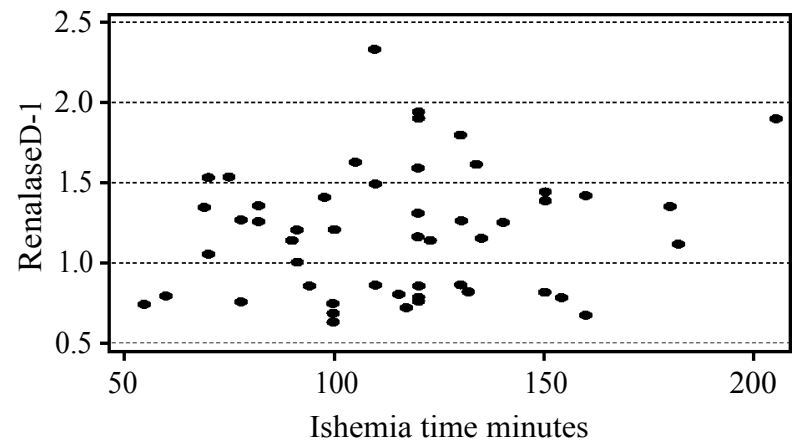

Fig. (1): Correlation between renalase at day 1 and graft ischemia time.
Table (1): Mean and SD of different laboratory parameter on day one and seven.

\begin{tabular}{llll}
\hline The studied parameter & Day 1 & Day 7 & $p$-value \\
\hline Liver biochemical profile: & & & \\
Total bilirubin (mg/dl) & $5.3 \pm 2.4$ & $5.3 \pm 5$ & 0.94 \\
Direct bilirubin (mg/dl) & $2.8 \pm 1.1$ & $3.9 \pm 1.1$ & 0.20 \\
AST (u/l) & $375 \pm 230$ & $91 \pm 72$ & 0.001 \\
ALT (u/l) & $296 \pm 210$ & $143 \pm 85$ & 0.002 \\
Albumin (g/dl) & $3.2 \pm 1$ & $2.7 \pm 0.4$ & 0.13 \\
Total protein (g/dl) & $4.7 \pm 1.2$ & $4.4 \pm 2$ & 0.84 \\
INR & $2.2 \pm 0.7$ & $1.4 \pm 0.3$ & 0.000 \\
GGT (u/l) & $45.4 \pm 19$ & $118 \pm 60$ & 0.000 \\
ALP (u/l) & $49.5 \pm 16$ & $135 \pm 50$ & 0.000 \\
Kidney profile: & & & \\
Creatinine (mg/dl) & $1.06 \pm 0.6$ & $1.2 \pm 0.5$ & 0.13 \\
Urea (mg/dl) & $44.8 \pm 19$ & $62 \pm 56$ & 0.002 \\
Electrolytes: & & & \\
Sodium (mEq/l) & $136 \pm 4.8$ & $132 \pm 5$ & 0.02 \\
Potassium (mEq/l) & $4 \pm 1.1$ & $3.9 \pm 0.5$ & 0.68 \\
Uric acid (mg/dl) & $3.9 \pm 1.1$ & $4.2 \pm 1.4$ & 0.88 \\
Complete blood count: & & & \\
Hemoglobin (g/dl) & $8.9 \pm 2.5$ & $9.2 \pm 1.2$ & 0.77 \\
Total leucocyte count & $8.7 \pm 2$ & $9.4 \pm 6$ & 0.80 \\
Platelets & $88.6 \pm 30$ & $76 \pm 20$ & 0.003 \\
\hline
\end{tabular}

Table (2): Mean and SD of renalase on day one and seven.

\begin{tabular}{lccc}
\hline Variables & Day 1 & Day 7 & $p$-value \\
\hline Renalase $(\mathrm{ng} / \mathrm{ml})$ & $1.4 \pm 0.3$ & $1.25 \pm 0.4$ & 0.004 \\
\hline
\end{tabular}

\section{Discussion}

Hepatocytes are considered relatively resistant to IRI because of their extensive antioxidant defense mechanisms and their existence within the comparatively hypoxic hepatic environment [7]

Hepatic Ischemia-Reperfusion Injury (IRI) as suggested by prolonged intraoperative time, anhepatic phase and any complications including bleeding represent an event with global repercussions reaching remote organs such as lungs, kidneys adrenals and myocardium. This is partially may be related to the oxidative burst and inflammatory response following graft reperfusion [8]. Alleviating ROS-burst in oxidative stress is an effective way to halt the progression of hepatic I/R injury.

Previous studies tried to demonstrate the severity of oxidative stress using different biomarkers such as Malondialdehyde (MDA) A [9] . Ascorbic Acid (AA)/Dehydroascorbic Acid (DHA) [10] and a series of inflammatory, proinflammatory, or antiinflammatory biomarkers [11].

Renalase, a recently identified flavoprotein, which is strongly expressed in kidney, heart liver, 
and skeletal muscles, effectively degrade catecholamines. Human renalase mRNA include 4 variants, Renalase isoenzyme 1 is well conserved, with signal peptide at the $\mathrm{N}$-terminal, a FAD-binding site and amine oxidase domain, Renalase has $13.2 \%$ amino acid identity of Monoamine Oxidase A (MAO-A), however it differs from MAO-A when it comes to catecholamine's degradation [4]. Sympathetic activity and generation of peroxidant molecules are vital in liver fibrosis and cirrhosis. In experimental liver cirrhosis impaired secretion of renalase into blood may lead to organ damage and sympathetic overactivity [12]

Liver transplantation has a major effects on systemic hemodynamic of cirrhotic patients. The initial phases of transplantation surgery are characterized by clamping of great abdominal and thoracic vessels to allow the removal of the native liver; after positioning of the donor liver and reestablishment of arterial-venous connections, there is a sudden increase in cardiac preload and pulmonary capillary wedge pressure in the presence of reduced mean arterial pressure, resulting in a high hemodynamic stress [13]

In this study we tried to demonstrate whether if renalase can be used as a potential biomarker of hepatic ischemia reperfusion injury following living donor liver transplantation especially when combined with the standard LFT panel resulting in more accurate and specific evaluations of the hepatic I/R injury can be made, we also tried to demonstrate if prolonged intraoperative ischemia time correlates to renalase levels.

By comparing different laboratory data day seven to laboratory data on day one, there was a statistically significant decline regarding AST, ALT, INR reflecting graft function. This agree with Moon D. \& Lee S., who found that liver enzymes improve following liver transplantation surgery, as ischemia and reperfusion injury resolve [14]

We did not find in our study statistically significant correlation between serum renalase levels and operative ischemia time suggesting ischemia reperfusion injury. This disagree with the study done by $\mathrm{Li}, \mathrm{H}$. and his colleagues demonstrating increased Renalase expression and histologic damage in hepatic I/R Injury Mouse models [15]

Jassem and his colleagues demonstrate for the first time that living donor liver allografts with minimal ischemia times are less likely to experience endothelial dysfunction with minimal platelet deposition and neutrophil infiltrates after reperfusion [16]
In the future, clinical treatment decisions based on the detection of renalase activities in the blood may help to improve the clinical outcomes of liver transplantation.

\section{References}

1- FONDEVILA C., BUSUTTIL R.W. and KUPIECWEGLINSKI J.W.: Hepatic ischemia/reperfusion injurya fresh look. Exp. Mol. Pathol., 74: 86-93, 2003.

2- JAESCHKE H.: Molecular mechanisms of hepatic ischemia-reperfusion injury and preconditioning. Am. J. Physiol. Gastrointest. Liver Physiol., 284: 15-26, 2003.

3- SCHULZE-BERGKAMEN H., SCHUCHMANN M., FLEISCHER B. and GALLE P.R.: The role of apoptosis versus oncotic necrosis in liver injury: Facts or faith? J. Hepatol., 44: 984-93, 2006.

4- LI X., HUANG R., XIE Z., et al.: Renalase, a new secretory enzyme: Its role in hypertensive-ischemic cardiovascular diseases. Medical science monitor: International Medical Journal of Experimental and Clinical Research, 20: 68892, 2014.

5- MORAN G.R.: The Catalytic Function of Renalase: A Decade of Phantoms. Biochim. Biophys. Acta., 1864 (1): 177-86, 2016.

6- ZHAO B., ZHAO Q., LI J., TAO XING T. and WANG F.: Renalase Protects against Contrast-Induced Nephropathy in Sprague-Dawley Rats. PLoS One, 10 (1): e0116583, 2015.

7- GONZALEZ-FLECHA B., CUTRIN J.C. and BOVERIS A.: Time course and mechanism of oxidative stress and tissue damage in rat liver subjected to in vivo ischemiareperfusion. J. Clin. Invest., 91: 456-64, 1993.

8- NASTOS C., KALIMERIS K., PAPOUTSIDAKIS N., et al.: Global consequences of liver ischemia/reperfusion injury. Oxidative medicine and cellular longevity, p.906965, 2014.

9- PINELLI, TRIVULZIO S., BRENNA S. and ROSSONI G.: "Plasma cardiac necrosis markers C-troponin-i and creatine kinase, associated with increased malondialdehyde levels, induced in rabbits by means of 5-aminolevulinic acid injection," Pharmacology, 84 (5): 314-21, 2009.

10- LYKKESFELDT J., LOFT S. and POULSEN H.E.: "Determination of ascorbic acid and dehydroascorbic acid in plasma by high-performance liquid chromatography with coulometric detection- are they reliable biomarkers of oxidative stress?" Analytical Biochemistry, 229 (2): 329-35, 1995.

11- DINARELLO C.A.: "Proinflammatory cytokines," Chest, 118 (2): 503-8, 2000.

12- SANSOÈ G., ARAGNO M., MASTROCOLA R., AYOUBI M. and PAROLA M.: In experimental liver cirrhosis impaired secretion of renalase into blood may lead to organ damage and sympathetic overactivity. Digestive and Liver Disease, 49 (1): 20, 2017.

13- RAVAL Z., HARINSTEIN M.E., SKARO A.I., et al.: Cardiovascular risk assessment of the liver transplant candidate. J. Am. Coll. Cardiol., 58: 223-31, 2011. 
14- MOON D. and LEE S.: Liver Transplantation Gut Liver, 3 (3): 145-65, 2009.

15- LI H., GUO J., LIU H., NIU, WANG Y., HUANG K. and WANG J.: Oxidative Medicine and Cellular Longevity: Article ID 3178562, 11 pages, 2016.
16-WAYEL J., KOO DICKEN D.H., LUCIA C., MOHAMED R., NIGEL D.H. and SUSAN V.F.: Cadaveric versus living-donor livers: Differences in inflammatory markers after transplantation. Transplantation, 76 (11): 1599-603, 2003.

\section{(Renalase)

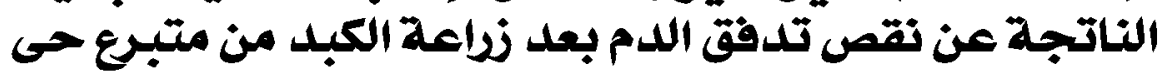

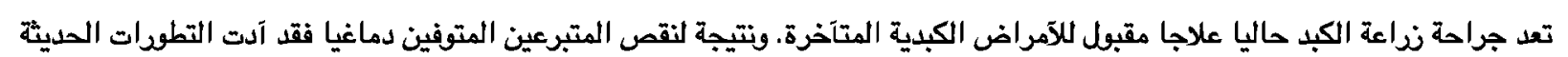

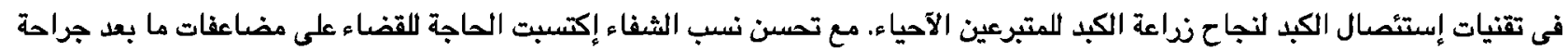
نراعة الكبد آهمية كبرى.

يعتبر نقص تدفق الدم الكبد المزبوع من آهم الآسباب المؤدية لإرتفاع إنزيمات الكبد مما يؤثر على كفاءة الكبد المزبوع من المتبرع الحى. ومن هذا المنطلق كان الهدف من هذه البحث إلقاء الضوء على الرينالز كدلالات حيوية جديدة للكثف المبكر عن مضاعفات نقص تدفق الدم اللكبد المزبوع.

آظهرت الدراسة وجود إنخفاض له دلالة إحصائية فى إنزيمات الكبد مع علم وجود علاقة بين معدلات الرينالز وطول فترة عملية ندع الكبد بعد إسبوع مقارنة باليوم الآول بعد العملية.

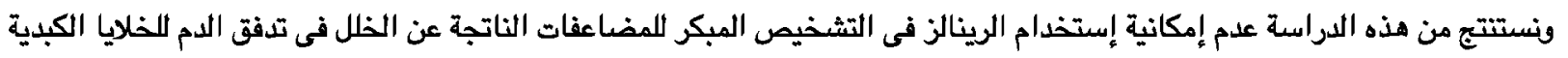

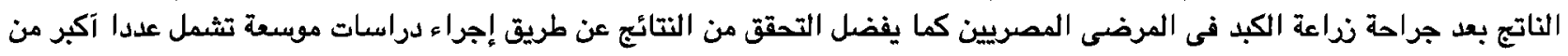

